\title{
Cinco urnas cinerarias del Museo Arqueológico Nacional
}

\section{Five funerary urns of the Museo Arqueológico Nacional}

\author{
Ana María SuÁrez Huerta* \\ Visiting Scholar. Yale Center for British Art
}

\begin{abstract}
RESUMEN
En el Museo Arqueológico Nacional de Madrid se conservan, en calidad de depósito, cinco urnas cinerarias. Desde su ingreso en el museo en 1868 habían sido catalogadas como obras romanas del siglo I d.C.

Este artículo revela datos acerca de la procedencia de las piezas $y$, tomando en consideración el estudio epigráfico y decorativo, las consideramos recreaciones realizadas a partir de inscripciones ya existentes o falsas en el contexto de la industria del souvenir all'antica que se desarrolló en la Roma de la segunda mitad del siglo XVIII con ocasión de satisfacer la demanda de los viajeros del Grand Tour.
\end{abstract}

ABSTRACT In the National Archaeological Museum in Madrid are preserved as deposit five funerary urns. Since joining the museum in 1868, they have been catalogued as Roman works from the First Century,A.D. This article reveals information about the origin of the pieces. Taking into consideration the epigraphic and decorative study, they can be considered recreations made from existing or false entries in the context of the souvenir all'antica industry that developed in Rome during the second half of the Eighteenth Century in response to demand by travellers of the Grand Tour.

\section{PALABRAS CLAVE}

Urnas cinerarias, recreaciones, souvenir all'antica, Grand Tour

\section{KEYWORDS}

Funerary urns, recreations, souvenir all'antica, Grand Tour

En 1867 se logró, tras un largo proceso, crear el Museo Arqueológico Nacional que tuvo su primera sede en el Casino de la Reina ubicado en el barrio de Embajadores. Con el fin de crear un fondo fundacional se reunieron algunas antigüedades que por decreto aportaron otros museos y colecciones públicas de Madrid. Este es el caso de cinco urnas de mármol que se conservan actualmente en dicho

* Dirección postal: C/Valdebrnardo, 20, 7 C. 28030 Madrid. Email: anamash2002@ hotmail.com 
museo. Habían llegado en 1783 a la Real Academia de Bellas Artes de San Fernando procedentes de Málaga, puerto al que había ido a parar un cargamento de arte y antigüedades que viajaba en un barco llamado Westmorland que fue capturado durante los últimos días del mes de diciembre de 1778 o los primeros días del mes de enero de $1779^{1}$. La carga de dicha nave fue adquirida por el rey Carlos III y trasladada a la institución madrileña por orden del Primer Secretario de Estado, el conde de Floridablanca. Entre las piezas se incluían:

«Quar [sic] Cinco urnas cinericias de marmol con varios ornatos». «En realidad, se trata tal y como aparece descritas en la documentación de: dos urnas sepulcrales de marmol con una tapa e inscripciones antiguas, adornadas de festones, animalillos \& la una cuadrada, y la otra redonda, y, tres urnas cinerarias, ó sepulcrales de marmol con dibersos ornatos: dos de ellos con una cubierta e inscripciones y una sin inscripción ni cubierta»².

Debido a que una de ellas es circular, en un primer momento, se descartó la posibilidad de que pudiera tratarse de una urna. Por esta razón, en la lista que se redactó fueron contabilizadas tan sólo cuatro pero, enseguida, se enmendó el error registrándose cinco urnas cinerarias.

Dos de ellas se encontraban en el «cajón $L$ con peso 49 @ y 5 , y tres en caxon cuyo peso $37 @$ y 10». Hasta el momento, nos ha sido imposible averiguar la identidad de los destinatarios.

Desde su ingresó en la Academia se las consideró antiguas y, en muy poco tiempo, se perdió por completo la información acerca de su procedencia. Tan sólo setenta años después, Emil Hübner, en su estudio sobre las esculturas antiguas de Madrid, no pudo dar ningún dato acerca de la procedencia de estas piezas ${ }^{3}$.

En una carta del director del Museo Arqueológico Nacional dirigida al Ministro de Instrucción Pública, José Amador de los Ríos, fechada el 30 de marzo de 1868, comunica de la siguiente forma el depósito de estos objetos:

«Al Director general de Instrucción pública digo con fecha de hoy lo que sigue: IImo. Señor. La Real Academia de las tres Nobles artes de San Fernando, deseosa de contribuir á los elevados propósitos de S.M. la Reina (q.D.g.) ha depositado en el Museo Nacional de Antigüedades por el unánime voto de sus individuos, cuantos objetos arqueológicos poseía dignos de figurar en dicho Central Establecimiento. Y SM. se ha servido mandar se den públicamente las gracias, á la Real Academia de San Fernando, por medio de la Gaceta, en señal de particular agrado con que ha visto este acto de desprendimiento y patrimonio. De Real orden lo traslado á VY. Para los efectos oportunos. Dios guarde á S.M. Muchos años»4.

\footnotetext{
1 SUÁREZ HUERTA, A.M.: «Un barco inglés en el puerto de Livorno» en VV.AA.: Arte y artistas del Westmorland, Sevilla, El Monte, 2002, pp. 49-68; LUZÓN NOGUÉ, José M. ${ }^{a}$, El Westmorland,obras de arte de una presa inglesa. Discurso leído por el académico electo, Excmo. Sr. D. José María Luzón Nogué, Madrid, 2000.

2 Real Academia de Bellas Artes de San Fernando (ASF), Archivo-Biblioteca, legajo, 4-87-1.

3 HÜBNER, E: «Die sammlung der Kunstakademie und des Naturhistorischen Museums», Die antiken Bildwerke in Madrid, capítulo IV, Berlín, 1862.

${ }_{4}$ Museo Arqueológico Nacional (MAN), Archivo, Exp. 1868/94.
} 
El 16 de mayo de este mismo año ya se encontraban las piezas depositadas en el Museo Arqueológico Nacional, tal y como hace constar la siguiente carta del director del Museo Arqueológico Nacional dirigida al Ministro de Fomento:

«La Real Academia de las tres Nobles Artes de San Fernando, deseosa de contribuir á los elevados propósitos de S.M. la Reina (q.D.g.), consignados en los reales decretos de 20 de Marzo y 12 de Junio del año último, há depositado en este Museo Nacional de Antigüedades, previo recuerdo tomado en junta general de 20 del próximo pasado Abril, por el unánime voto de sus individuos, cuantos objetos arqueológicos poseía, dignos de figurar, con honra suya y provecho de los estudiosos, en este central establecimiento. Son notables entre todos, cuatro bellas urnas cinerarias de exquisito mármol blanco, dos de las cuales pertenecen á la más gloriosa edad de las artes romanas, un cipo debido así mismo a la civilización latina»5.

En la documentación del Museo Arqueológico Nacional aparece registrado el ingreso en calidad de depósito de las cinco urnas procedentes de la Real Academia de Bellas Artes de San Fernando del siguiente modo:

«Nota de los objetos pertenecientes a esta Real Academia que pasan en calidad de depósito al Museo Arqueológico Nacional ${ }^{6}$.

Una urna cineraria de mármol blanco con su tapa y la siguiente inscripción = D.M. = G.N. VOLUNTILI. = SESTI. FEC. Está adornado con festones de frutas, cabezas de carnero, fronton y bocatejas de mascaranos \&: es de $20 \times 13 \times 21$ pulgadas $=$ á $0^{\mathrm{m}}, 49 \times 0^{\mathrm{m}} 34 \times 0^{\mathrm{m}}, 47$.

Una urna cineraria de mármol blanco con su tapa y la siguiente inscripción = D.M. A. CORNELIVS-APRILIS. CORNE = LIAE. NYMPHAE. ET ALBANAE-CATELLAE. B. M. F. Dos genios sostienen una corona cívica, en cuyo centro se halla el busto del finado. Los ángulos de la misma figuran trípodes, á los costados hay unos hipogrifos; tiene frontón y rosetones en sus ángulos \&: es de $161 / 2 \times 15 \times 12$ pulgadas $=0^{\mathrm{m}} 34=0^{\mathrm{m}}, 25=0^{\mathrm{m}} 36$.

Una urna cineraria de mármol blanco y su tapa con la siguiente inscripción = DM $=$ ANTONIAE.MAX-VMAE = ANTONIAE MODESTAE. LAVRENTIVS GENER MARITVS-EX TESTAMENTO = tiene caireles de laurel, águilas, romanato y rosetones en su tapa \&: es de $21 \times 15$ y por 20 pulg. $^{s}=0^{m}, 49 \times 0^{m}, 36=0^{m}, 48$.

Una urna cineraria de mármol blanco sin tapa ni dedicatoria, con festones, quimeras, cabezas de carnero $\&=15 \times 14 \times 9$ pulg. $^{s}=0^{m}, 35 \times 0^{m}, 31 \times 0^{m}, 20$.

Un cipo de forma cilíndrica de 14 pulgadas de diámetro por otro tanto de alto, sencillo y dedicado á LIVIA VENVTA.

Diámetro $0^{m} 30$, altura $0^{m} 33$ ».

Al ingresar en un museo con especialistas en epigrafía no pasaron desapercibidas las sospechas acerca de su manufactura, sin embargo, fueron publicadas por primera vez en el primer volumen del Museo Español de Antigüedades en 1877 donde se daban someros datos acerca de su procedencia ${ }^{7}$. Mariano Catalina fue el

5 Ibidem.

6 Ibidem.

7 CATALINA, M.: «Urnas cinerarias con relieves del Museo Arqueológico Nacional», Museo Español de Antigüedades, I, (1877), pp. 511-539. 
primero que se enfrentó al estudio de estas urnas y consideró que, dado el carácter artísticamente romano de las urnas y la utilización de una decoración en la que aparecen representados todos los emblemas y símbolos de la mitología romana, descartaba la posibilidad de que se tratase de obras posteriores al período romano. No obstante, como veremos a lo largo de la exposición de este artículo, podemos decir que estas urnas, en su conjunto, constituyen un conglomerado de varios siglos de práctica decorativa puesto que en ellas se dan cita varios estilos que pueden datarse en épocas distintas y motivos claramente modernos.

\section{LAS URNAS CINERARIAS ROMANAS COMO ELEMENTOS DECORATIVOS EN EL SIGLO XVIII}

El viaje a Italia, también denominado Grand Tour, brindaba la oportunidad de atravesar diversos territorios europeos y, como peregrinos de una «nueva religión», admirar lo que en cada piedra parecía estar inscrito, es decir, las palabras sic transit. En la segunda mitad del siglo XVIII el ferviente deseo por adquirir antigüedades llevó a la venta de numerosas de colecciones y a la realización de excavaciones sistemáticas en los alrededores de Roma. De esta forma, el comercio y la restauración aumentaron proporcionalmente a la demanda. Adolf Michaelis, el más importante cronista de ese momento, lo denominó el Golden Age of Classical Dilettantism en Gran Bretaña ${ }^{8}$.

Las ruinas de la ciudad de Roma se convirtieron en una importante fuente de motivos ornamentales y mina de interesantes curiosidades evocadoras. Las urnas cinerarias romanas fueron uno de los objetos predilectos del coleccionismo británico y, aunque no existe base documental para afirmar que este tipo de piezas se adquiriesen de forma engañosa o fuesen vendidas como auténticas antigüedades, en ocasiones, se ha tildado a los británicos de voraces y proclives a conformarse con cualquier cosa que cayese en sus redes. De ser cierto, esta apreciación dejaría en muy mal lugar a los italianos pues, en este caso, serían considerados meros tenderos de antiguallas ${ }^{9}$.

Ante el aluvión de demanda que trajo consigo el Grand Tour el Estado Pontificio se vio obligado a crear una legislación específica relacionada con la extracción del Alma Cittá, como así era denominada la ciudad de Roma, de bienes arqueológicos y artísticos, con el fin de conservar el inmenso patrimonio cultural. En un edicto promulgado por el cardenal Annibale Albani en 1733, se introdujo un aspecto nuevo en la legislación llegándose a la conclusión de que debían adoptarse medidas de control ante el gran atractivo que, en los viajeros, despertaban las obras de escultura y pintura. Se dictaron de un modo minucioso toda una serie de medidas cautelares relacionadas con las actividades arqueológicas, las exportaciones de obras y objetos artísticos e incluso se contemplaron las penas en relación al negocio de falsificaciones ofertadas, siempre y cuando estas fuesen ven-

\footnotetext{
8 MICHAELIS, A.: Ancient Marbles in Great Britain, Cambridge, 1882.

9 BIGNAMINI, I.: «Gran Tour: Open Issues», en BIGNAMINI, I. y WILTON, A.: Gran Tour. The Lure of Italy in the Eighteenth Century, Londres, Tate Gallery, 1996, pp. 31-35.
} 
didas como verdaderos antiguos ${ }^{10}$. El superintendente de antigüedades estudiaba detenidamente cada caso. En ocasiones, se llevaba a cabo una petición de extracción para una obra, declarando únicamente la presencia de restauraciones modernas y la escasa calidad del material cuando lo que se pretendía, en realidad, era exportar una obra de mayor importancia de lo que se había manifestado en la petición de licencia de exportación ${ }^{11}$.

A pesar de que los británicos exportaron gran cantidad de piezas y, el negocio de venta y exportación solía ser fraudulento, lo cierto es que, salvo en algún caso aislado, no sacaron de Italia ninguna obra de primer orden ${ }^{12}$. La mayor parte de las piezas que se enviaron a Gran Bretaña fueron mármoles procedentes de excavaciones que habían sido previamente restaurados en talleres romanos. De la misma forma que la sociedad británica valoraba su pasado y las familias de linaje decoraban sus mansiones con infinidad de retratos, los romanos se encomendaban a los dioses Manes para su protección eterna a través de las urnas cinerarias. Para un británico, por tanto, poseer este tipo de objetos significaba mantener vivo el hilo conductor con el pasado. Un poema de John Dyer resume a la perfección la percepción obtenida frente a las ruinas romanas:

Fall' fall'n a silent Heap; her Heroes all

Sunk in their Urns; behold the Pride of Pomp,

The Throne of Nations fall'n; obscur'd in dust;

Ev'n yet Majestical...13

Si el Grand Tour generó el fenómeno del coleccionismo a gran escala no es casual encontrar datos que atestigüen la actividad de artistas que aprovecharon y se beneficiaron de esta situación. Este es el caso del famoso restaurador de antigüedades Bartolomeo Cavaceppi ${ }^{14}$ y del arquitecto, grabador y teórico del arte,

10 EMILIANI, A.: Leggi, bandi e provvedimienti per la tutela dei beni artistici e culturali negli antichi stati italiani, 1571-1860, Bolonia, Alfa, 1978, pp. 90-96.

${ }^{11}$ SUÁREZ HUERTA, A. M.: «Arte y artistas del Westmorland. El comercio de arte y antigüedades en la segunda mitad del sigo XVIII» XV Congreso de Historia del Arte organizado por CEHA (Comité Español de Historia del Arte), Palma de Mallorca, 20-23 de octubre de 2004.

12 BERTOLOTTI, A.: «Esportazione di oggetti di Belle Arti da Roma nei secoli XVI, XVII, XVIII e XIX», Archivio storico artistico archeologico e letterario della città e provincia de Roma, vol. I, (1875), Roma.

${ }_{13}$ The Ruins of Rome, Londres, 1740.Citado por HONOUR H.: Neoclasicismo, Madrid, Akal, 1991, pág. 90.

Caída, caída, callada Pila; sus Héroes todos

Hundidos en sus Urnas; mirad el Orgullo de la Pompa,

El Trono de las Naciones caído; obscurecido en el polvo;

Y aún Majestuoso.

${ }^{14}$ Bartolomeo Cavaceppi (1716-1799) fue el restaurador más importante de la segunda mitad del siglo XVIII en Roma. Se formó junto al escultor francés Monnot y más tarde en la Accademia di San Luca de Roma. Se especializó en la restauración de esculturas antiguas y trabajó para importantes colecciones como la del cardenal Albani, el conde Fede, el representante español ante la Santa Sede, José Nicolás de Azara, o la colección de escultura de los Museos Capitolinos y el Vaticano. Su trabajo fue muy reconocido en el Reino Unido, y los británicos se convirtieron en su clientela más numerosa. Winckelmann se refería a su estudio como il museo Cavaceppi, ya que almacenaba gran cantidad de antigüedades de interés y contaba con una innumerable colección de fragmentos antiguos, llegando a contar con más de mil mármoles antiguos, muchas copias y moldes. 
Giovanni Battista Piranesi ${ }^{15}$, que fueron capaces de convertir esta demanda en un próspero negocio. No sólo se dedicaron a las tareas artísticas sino que además, estableciendo un meditado proyecto de promoción de sus obras, lograron tejer una tupida red de relaciones con el fin de acoger a la mayor cantidad posible de clientes. Contactaban con los viajeros a través de agentes comerciales dedicados al tráfico de obras de arte y antigüedades y solicitaban permisos ante el Comisario de Antigüedades de Roma con el fin de hacer llegar los encargos a destino.

El gusto de los coleccionistas por la restauración produjo el perfeccionamiento de las técnicas y el sistema de trabajo. Las integraciones pasaban por la arcilla, el yeso y el mármol. Bartolomeo Cavaceppi se especializó en la restauración de esculturas antiguas. Trabajó para importantes colecciones y se enriqueció gracias a las ventas. Para la colección de Henry Temple, el segundo vizconde Palmerston de Broadlands, restauró en 1768, estatuas, relieves, urnas y bustos y para la colección de William Petty-Fitzmaurice, el segundo conde de Shelburne, en 1771 restauró la urna cineraria de Nicostratus ${ }^{16}$. El agente comercial Thomas Jenkins compró a Cavaceppi cincuenta mármoles para lord Shelburne entre los que había pedestales, cipos, aras, altares y urnas. A su vez, el Papa Clemente XIV le encargó comprar para el Museo Pío-Clementino una urna o sarcófago con una batalla de gigantes y unas urnas romanas ${ }^{17}$. Utilizaba los mármoles antiguos como elemento de añadido para las restauraciones o bien un pezzo antico a partir del cual crear una nueva pieza de forma que el restaurador pudiese ser también considerado creador (Fig. 1).

Para los británicos era imprescindible que las obras estuviesen restauradas quizá en el ánimo de retomar las afirmaciones de Vasari, según el cual, una figura sin miembros no era agradable a la vista ${ }^{18}$. No obstante, y aunque lo que interesaba era dar salida a todas las piezas antiguas, lo cierto es que y, aunque parezca contradictorio, las ideas estéticas de Cavaceppi son importantes ya que fue el primer restaurador que elaboró una nueva visión de la estatuaria antigua exenta de restauración ${ }^{19}$.

15 Giovanni Battista Piranesi (1720-1779) se formó como arquitecto en Venecia afincándose en Roma en 1744. Fue el abanderado de la facción pro-romana en la encarnizada discusión que tuvo lugar en el siglo XVIII en relación a los respectivos méritos de la arquitectura griega- cuyo máximo defensor fue Winkelmann- y la arquitectura romana. Su obra se caracteriza por un uso teatral del claroscuro y una desmesurada imaginación que proponen nuevos conceptos de la masa y el espacio. Su mensaje pretendía liberarse de la teoría académica para crear un estilo inspirado en la arquitectura romana que no fuese estrictamente imitativo. La difusión de su obra consiguió crear un imaginario colectivo del mundo antiguo romano y ocasionó, no pocas, decepciones entre aquellos que se acercaban por primera vez a la Antigüedad teniendo en la retina sus imágenes.

${ }_{16}$ CAVACEPPI, B.: Raccolta d'antiche statue busti teste cognite ed altre sculture antiche suelte ristaurate da Bartolomeo Cavaceppi scultore romano, vol. III, Roma, 1772, lámina 12.

17 Ibidem, lámina 55.

18 VASARI, G.: Le vite dei più eccellenti pittori, scultori e architetti, Newton \& Compton, Roma, 2001, pp. 32 у 33.

19 CAVACEPPI, B.: op. cit., Roma, 1769. En esta obra dibuja todas aquellas obras de su propiedad o aquellas que habían pasado por sus manos organizándolas cronológicamente desde 1764al 1772, creando de esta forma un catálogo muy valioso para la visión de la estatuaria en aquella época. CAGIANO DE AZEVEDO, M.: II gusto del restauro, Olympus, Roma, 1948. 
como verdaderos repertorios destinados a una suerte de venta por catálogo. Una de las prácticas habituales de Piranesi consistía en dedicar alguna de sus estampas a sus más preciados clientes, de esta forma, no sólo elogiaba a su clientela sino que esta práctica le permitía dar a conocer piezas halladas en excavaciones y describirlas pormenorizadamente, todo ello amenizado por su incansable imaginación lo que daba como resultado sugestivas recreaciones (Fig. 2).

Se difundió la utilización de textos tomados de inscripciones antiguas o creados ex novo para dar mayor autenticidad a estas antigüedades, tanto si eran piezas antiguas retocadas como falsificaciones. Piranesi recreó urnas cinerarias en los grabados de la serie, Vasi, candelabri, cippi, sarcofagi, tripodi, lucerne, ed or-

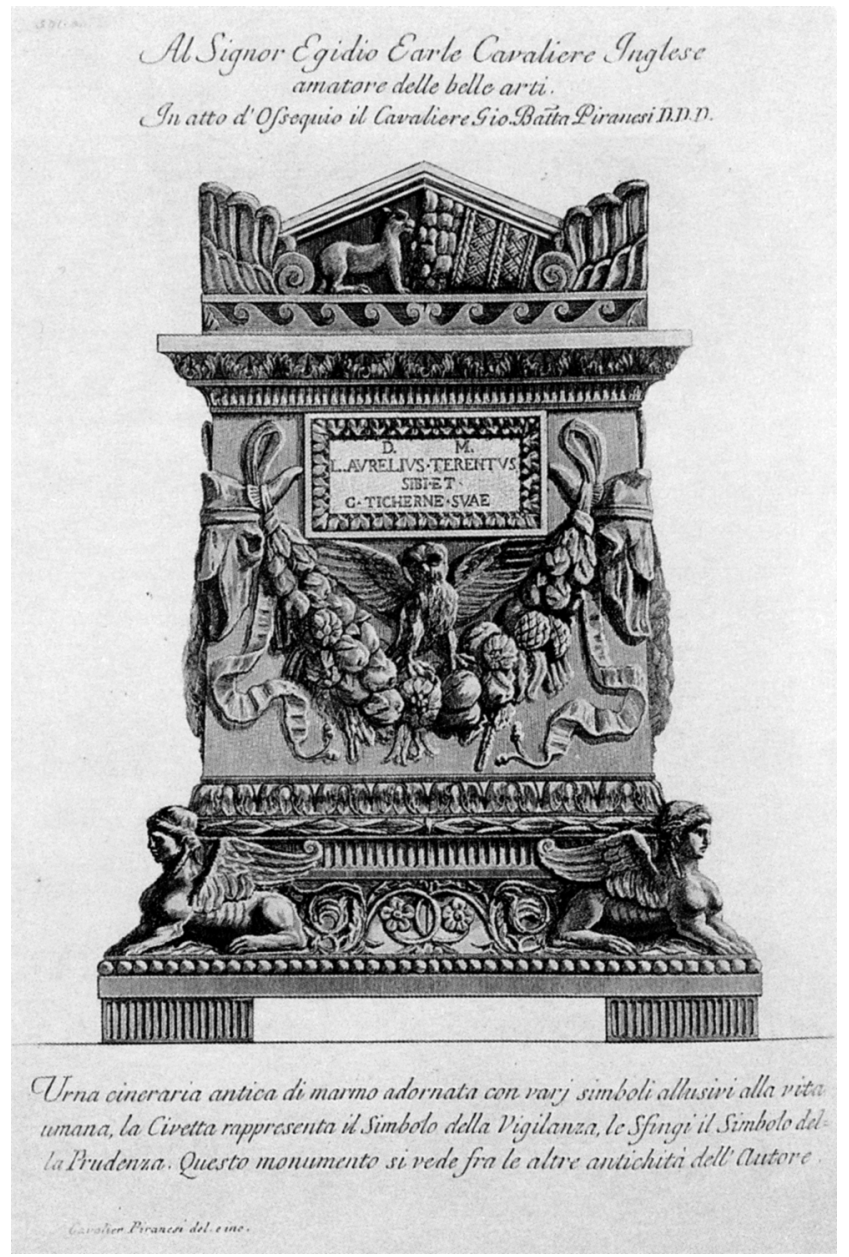

Fig. 2. Giovanni Battista Piranesi, Diseño de urna dedicada a Egidio Earle cavaliere inglese, Vasi, candelabri, cippi, sarcofagi, tripodi, lucerne, ed ornamenti antichi disegnati ed incisi dal Cav. Gio. Batt. Piranesi, Roma, 1778. 
namenti antichi disegnati ed incisi dal Cav. Gio. Batt. Piranesi publicati l'anno $M D C C L X X I I X^{21}$ y contaba con experiencia en la producción de inscripciones. De hecho, publicó obras como Lapides Capitoline ${ }^{22}$, realizó reproducciones de las Iscrizioni delle Camere sepolcrali d'Liberti, e Servi, ec, Della Famiglia di Augusto, que fueron incluidas en su obra sobre Le Antichità Romane IIR3. El artista italiano era capaz de hacer interesantes hasta los más mínimos fragmentos de epitafios gracias a sus potentes juegos de luces y sombras y a sus pintorescas composiciones.

Sin lugar a dudas, el aspecto de las urnas que se conservan en el Museo Arqueológico Nacional es similar al que presentan los dibujos de las urnas cinerarias restauradas por Bartolomeo Cavaceppi, destinadas al mercado inglés y al conjunto de obras reproducidas en las obras de Piranesi (Fig. 3). Este tipo de objetos son testigos directos de las intensas relaciones entre ambos artistas y la industria que crearon en torno «allo antico» 24 .

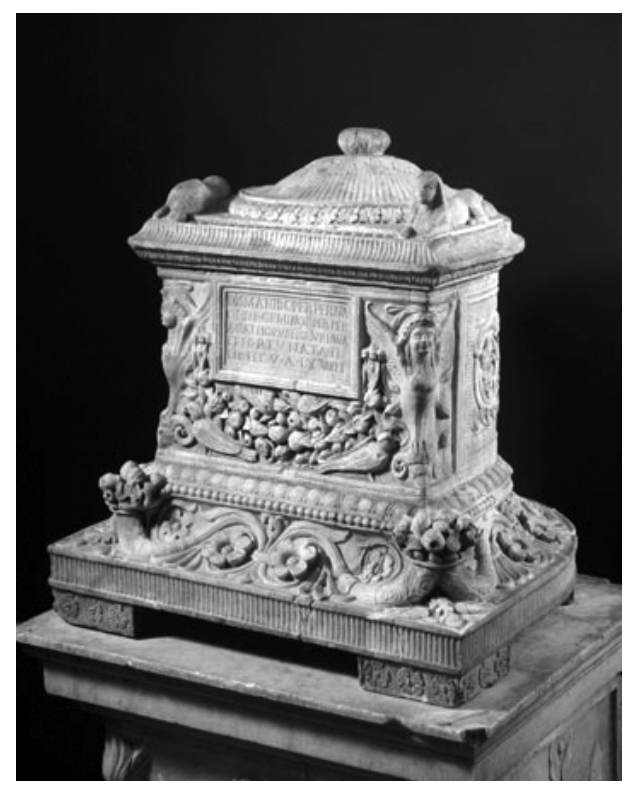

Fig. 3. Bartolomeo Cavaceppi, Urna cineraria, Lady Lever Art Gallery, Liverpool, n. ${ }^{\circ}$ inventario $L 11$.

21 PIRANESI, G. B.: Vasi, candelabri, cippi, sarcofagi, tripodi, lucerne, ed ornamenti antichi disegnati ed incisi dal Cav. Gio. Batt. Piranesi publicati l'anno MDCCLXXIIX. Roma, 1778.

${ }_{22}$ I. B. Pirasesii Lapides Capitoline sive Fati Consulares Triumphales romanorum ab urbe condita usque ad Tiberium Caesarem. Venueunt apud Auctorem in aedibus Comitis Thomatis via Felici prope templum SS. Trinitatis in Monte Pincio, Roma, 1762.

${ }^{23}$ Le Antichità Romane opera di Giambattista Piranesi architetto veneziano divisa in quatro tomi...In Roma MDCCLVI nella stamperia di Angelo Rotilj nel palazzo de'Massimi...S. vendono in Roma dai Signori Boucharde Gravier mercanti libraj al Corso presso San Marcelo, Roma, 1756.

${ }^{24}$ PIVA, C.: «La casa bottega di Bartolomeo Cavaceppi: un laboratorio di restauro delle antichità che voleva diventare una accademia», Richerche di Storia dell'Arte, 70, (2000), pp. 5-20. 
Las urnas alla maniera romana también habían sido fuente de inspiración en el Medioevo, en muchas ocasiones del mismo modo que ocurrió en el siglo XVIII. Un ejemplo muy sugestivo lo encontramos en los pedestales de las columnas en torno al crucero de la catedral de Siena (siglo XIII), donde se recrean urnas cinerarias romanas talladas en el siglo XIII por los canteros de la orden cisterciense que inició los trabajos de construcción. Mejor estudiado es el caso de las urnas de Amalfi reutilizadas en torno al siglo XII pero todas procedentes de Roma ${ }^{25}$. Aunque este caso no tiene nada que ver con el posterior coleccionismo de los aristócratas británicos, sin embargo, señala la misma inclinación e incorpora, en la propia cultura, objetos procedentes de las antiguas ruinas con la misma elocuencia que lo documenta el pedestal sienes. (Fig. 4).

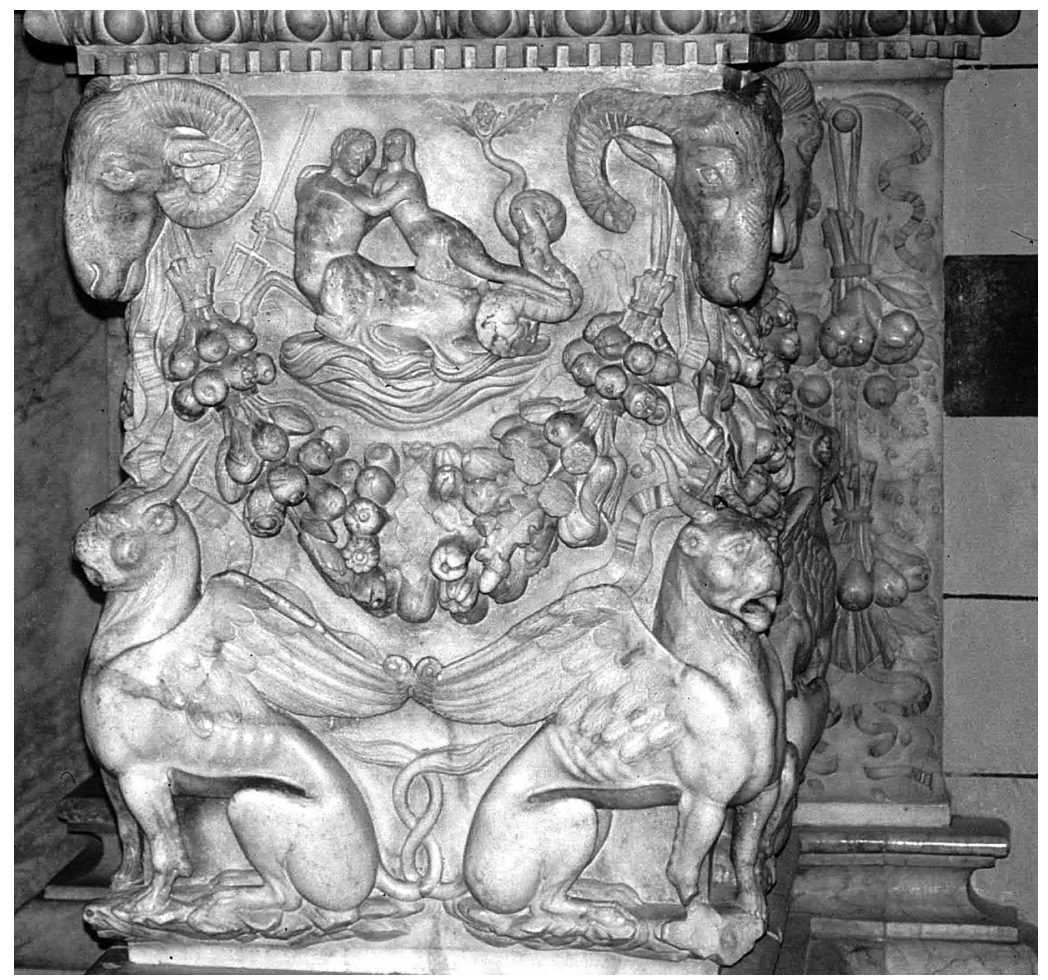

Fig. 4 Pedestal de una columna del crucero del Duomo de Siena (s. XIII).

A continuación pasaremos a analizar las características fundamentales de cada una de las urnas conservadas en el Museo Arqueológico Nacional que nos hacen dudar acerca de su origen «plenamente» romano.

25 MANACORDA, D.: «Amalfi: urne romane e commerci medievali» en Aparchai. Nuove ricerche e studi sulla Magna Grecia e la Sicilia antica in onore di Paolo Enrico Arias, II, (1982), pp. 713-732. 


\section{URNA SIN INSCRIPCIÓN²6 (Fig. 5)}

Con anterioridad al primer estudio realizado sobre las urnas del Museo Arqueológico Nacional, José Amador de los Ríos y Juan de Dios de la Rada y Delgado estudiaron una urna cineraria conocida como la «Urna de Filomena». La conclusión del estudio fue que se trataba de una copia realizada en el XVI en algún taller italiano. En cambio, otros anticuarios y epigrafistas pensaron que, esta urna era muy similar a las que se hallaban en el Museo Arqueológico procedentes de la Real Academia de Bellas Artes de San Fernando. Tras analizar la documentación pudieron observar cómo estas urnas desde su ingreso en esta institución habían sido consideradas antiguas. Catalina advertía que la persona encargada de redactar el inventario en la Academia era conocedora de este tipo de objetos y acertadamente los catalogó como antiguos ${ }^{27}$.

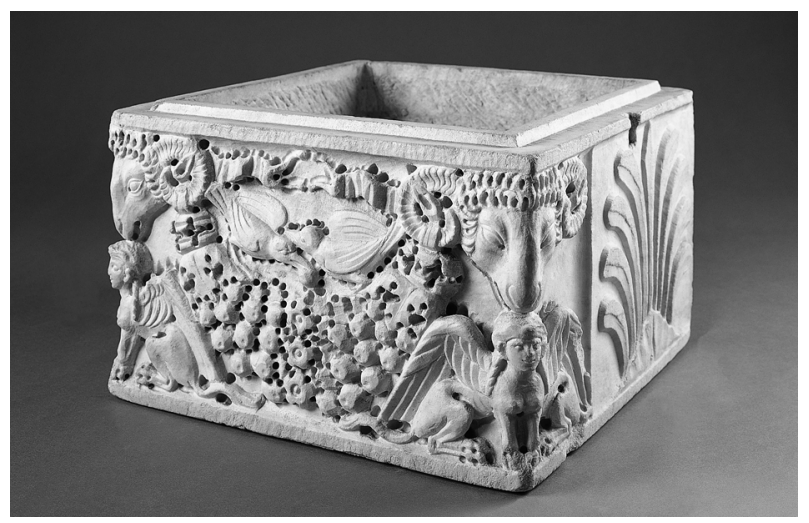

Fig. 5. Urna cineraria sin inscripción. Mármol, 22 × 35,4 x 33,3 cm. MAN, n. ${ }^{\circ}$ inv. 2844.

En la documentación de archivo, es decir, en la primera lista del primer desempaque, a la que se refiere Catalina, esta urna aparece descrita como: "urna sin tapa ni inscripción de pie y quadro y una cuadra cumplida de alto, a los angulos dos cabezas de carnero, de cuyas astas pende un feston, sobre este dos aves, debajo de dhas Cabezas unas esfinges ${ }^{28}$.

Presenta en los ángulos del frente dos cabezas de carnero representadas de un modo muy similar al que nos muestra Piranesi en algunas de sus láminas, de las que cuelga una guirnalda sobre la que dos avecillas picotean los frutos entrelazados en ellas (Fig. 6). Debajo de las cabezas de carnero encontramos dos esfinges, y en los costados de la urna dos palmas. Carece de cubierta y de inscrip-

\footnotetext{
${ }^{26}$ MAN, n. ${ }^{\circ}$ inv. 2844. Urna cineraria sin tapa ni inscripción 22 x 35,4 x 33,3 cm.

27 CATALINA, M., op. cit., pp. 533 y 534.

28 ASF, legajo, 4-87-1
} 


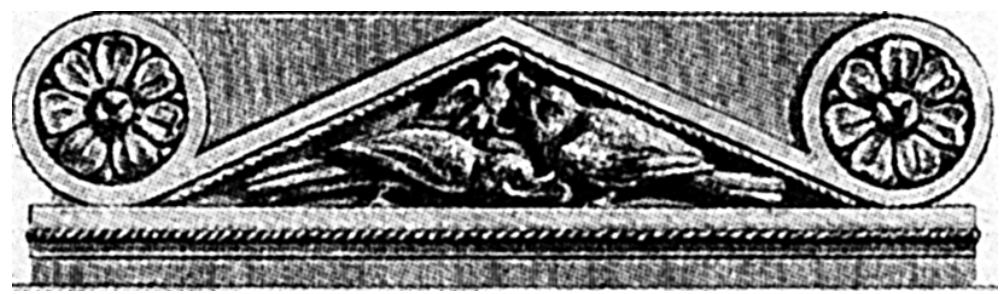

Fig. 6 Giovanni Battista Piranesi. Detalle del frontón del basamento en forma de urna cineraria de un vaso de la estampa Tre vasi en Vasi, candelabri, cippi, sarcofagi, tripodi, lucerne, ed ornamenti antichi disegnati ed incisi dal Cav. Gio. Batt. Piranesi, Roma, 1778.

ción y, es posible que pudiera estar incluida en la tapa. Aunque no era una práctica muy común en el mundo romano, en ocasiones las inscripciones podían aparecer sobre las tapas. Este podría haber sido el caso de esta urna pues más raro aún es encontrar urnas sin indicación alguna del nombre o circunstancias del difunto. Las cabezas de carnero aparecían muy frecuentemente en los monumentos funerarios romanos, pero debieron ser consideradas como un adorno puramente arquitectónico y escultórico, pues siempre que aparecen, sus cuernos tienen relación con otro objeto del bajorrelieve y principalmente con los festones y guirnaldas, cuyos extremos están en ellos sujetos con cintas.

En realidad, como veremos en otras urnas de este lote, nos referimos a la urna de Cneo Voluntilio Sesto y la de Antonia Maxuma, el motivo del prótomos carnero sosteniendo una guirnalda es un esquema compositivo empleado con profusión por Piranesi en modelos muy similares a este. Del mismo modo la guirnalda, poblada o no de animalillos, la utiliza en una disposición prácticamente idéntica a la que vemos en muchos de sus modelos. Los talleres romanos del siglo XVIII elaboran los distintos esquemas decorativos con una manufactura y acabados diversos pero siempre con una cierta pericia que podemos apreciar en el acabado de la parte central, siempre más elaborado que los laterales. La utilización del trépano y las características del dibujo, a veces, puede resultar engañoso para el especialista actual sino es advertido de que con toda probabilidad se trata de piezas modernas.

Iván Negueruela considera que esta urna debió de servir de modelo para la decoración de la fachada del Museo Arqueológico Nacional pues en ella encontramos una estatua de Berruguete en la que la figura se apoya en un soporte que parece estar inspirado en esta urna ${ }^{29}$.

29 NEGUERUELA, I.: «Piezas cedidas por la Real Academia de San Fernando» en VV.AA.: De Gabinete a Museo. Tres siglos de Historia. Museo Arqueológico Nacional, Madrid, Ministerio de Cultura, 1993, p. 270. 


\section{URNA CINERARIA DE LIVIA VENUSTA ${ }^{30}$}

En la documentación de la Academia aparece descrita en la «Primera lista de desempaque», remitida por el marqués de la Florida y Pimentel al conde de Floridablanca el 18 de octubre de 1783: "Caxon L con peso $49 @$ y 5 . Una basa Circular de marmol blanco de pie y quarto de alto y un pie de diámetro; con un recuadro al frente, y dentro esta inscripción: D.M Liviae venustae. C. Livius Fortunatus vxoris benemerenti. V.AN.XIX:M.IX contornado el recuadro de yedra y su frutilla: a un costado un vaso de vajo relieve y al otro costado un platillo» ${ }^{31}$. (Fig. 7).

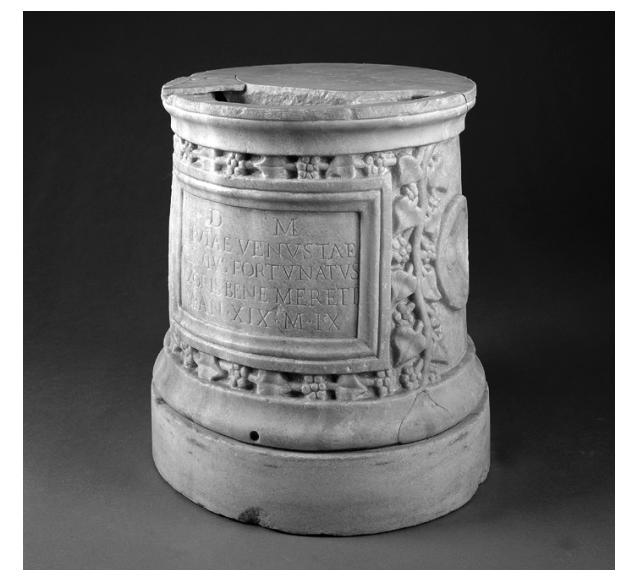

Fig. 7. Urna cineraria de Livia Venusta. Mármol, 30 x $33 \mathrm{~cm}$. MAN, n. ${ }^{\circ}$ inv., 1985/74/12.

Esta urna, dada su forma circular fue, en un primer momento, confundida con un pedestal o cipo. La tapa está incompleta y le ha sido añadido un pedazo en otro tipo de mármol. El interior se encuentra vacío y en el fondo se ha perforado un agujero. El tamaño de la urna sería demasiado pequeño para la introducción de la caja de plomo que contenía las cenizas.

Destaca por su inscripción enmarcada en una decoración esquemática de hojas de parra. En el lado izquierdo hay un praefericulum un tanto extraño por el modo en que aparece representado el pie y la voluta del mango. En la izquierda encontramos una pátera que presenta una forma demasiado circular. No obstante, la inscripción llama la atención por las erratas que presenta: D M LIVIAE VENVSTAE C LIVIVS FORTVNATVS UXORIS BENE MERETI V A N XIX M IX ${ }^{32}$. En primer lugar, la inclinación de las astas de la $\mathrm{M}$ es muy poco habitual. La grafía precisa del genitivo sería uxori (sic) y la grafía de la E de la palabra MERETI ha sido trabajada como si de una conjunción ET se tratase. Además, también aquí encontramos una errata pues faltaría

\footnotetext{
30 MAN, n. inv., 1985/74/12. Urna cineraria de mármol, 30 x $33 \mathrm{~cm}$.

${ }^{31}$ ASF, legajo 4-87-1.

32 CIL VI 29506.
} 
la $\mathrm{N}$ de merenti (sic). Este tipo de errores gramaticales difícilmente habrían sido cometidos en época romana ${ }^{33}$.

\section{URNA CINERARIA DE CNEO VOLUNTILIO SESTO34}

Esta urna es cuadrada y la tapa presenta forma de frontón con antefijas que representan máscaras teatrales. A simple vista se puede observar como la tonalidad del mármol es distinta con respecto al cuerpo de la urna, lo que puede indicar que, en un principio esta tapa no fuese concebida para esta pieza en concreto. Este tipo de urnas en las que se reproduce el esquema de una casa, solían presentar una tapa con forma de tejado a dos aguas, sin embargo, en este caso, tan sólo ha sido trabajada en la parte frontal, como si de un tímpano se tratase. En dicho tímpano aparece representado un jabalí en actitud de comer los frutos que salen de un canasto volcado, motivo que encontramos de forma idéntica en grabados de Piranesi, mientras dos conejos se disponen a ambos lados del tejado a dos aguas ${ }^{35}$. (Fig. 8). (Ver el tímpano de la urna representada en la Fig. 2).

En cada uno de sus ángulos del cuerpo de la urna se representan cabezas de carnero de cuyos cuernos cuelga una guirnalda que es picoteada por una especie de libélula. Este motivo, en el que las orejas del carnero aparecen un tanto alejadas

${ }^{33}$ SINN, F.: «Stradtrömische Marmorurnen», Beiträge zur Erschliessung hellenistischer und Kaiserzeitlicher Skulptur und Architektur, vol. 8, Mainz y Rhein, P. von Zabern 1987, p. 279.

34 MAN, n. ${ }^{\circ}$ inv. 2841. Urna cineraria. Mármol, $49 \times 47 \times 34 \mathrm{~cm}$

ASF, legajo 4-87-1. En la «Primera lisa de desempaque» remitida por el marqués de la Florida y $\mathrm{Pi}$ mentel al conde de Floridablanca el 18 de octubre de 1783 aparece descrita del siguiente modo: Caxon $L$ con peso 49@ y 5. Una urna de mármol banco de pie y tres de ancho; pie y octavo de fondo y un pie de tres cuartos de todo su alto con su tapa: recuadro al fr. ${ }^{\text {te }}$ y en el esta inscripción,

D.M.

CN VOLVNTILI

SESTI. FEC

La tapa hace frontispicio, en cuyo centro un javali come la fruta de un cesto derramado, a los extremos dos cabezas de muger junto á ellas dos liebres: a los angulos de la urna cabezas de carnero de cuyas astas pende un feston debajo unas aves cogiendo con el pico un lagarto. Los costados correspondientemente adornados.

35 En el Catálogo del Museo Arqueológico Nacional de 1833, Juan de Dios de la Rada y Delgado la describe como: Urna cineraria romana. Mármol. Tiene planta rectangular y friso de hojas de acanto; en el frente, dentro de un recuadro de relieve se lee:

D.M.

GN VOLVNTILI

SESTI FEC

(A LOS DIOSES MANES DE EGNEO VOLUNTILO SESTO, FECIAL) (SIC).

En la parte superior de los cuatro ángulos, decoran la urna cuatro cabezas de carnero infulados, de cuyos cuernos penden guirnaldas de hojas, flores y frutos que adornan el frente y las partes laterales; encima de la guirnalda del frente hay un insecto, quizá se trate de una cigarra; abajo y a la izquierda, un ave cogiendo por la parte anterior del cuerpo una lagartija por la parte posterior del cuerpo; la una sube y la otra baja por la guirnalda. Las guirnaldas de las partes laterales tienen una lagartija en su parte media. De la tapa se eleva un frontón cuyos ángulos inferiores están adornados con antefijas representando máscaras, y por los lados superiores suben dos conejos. En el tímpano se ve un jabalí en actitud de comer las frutas que salen de un cesto volcado. 


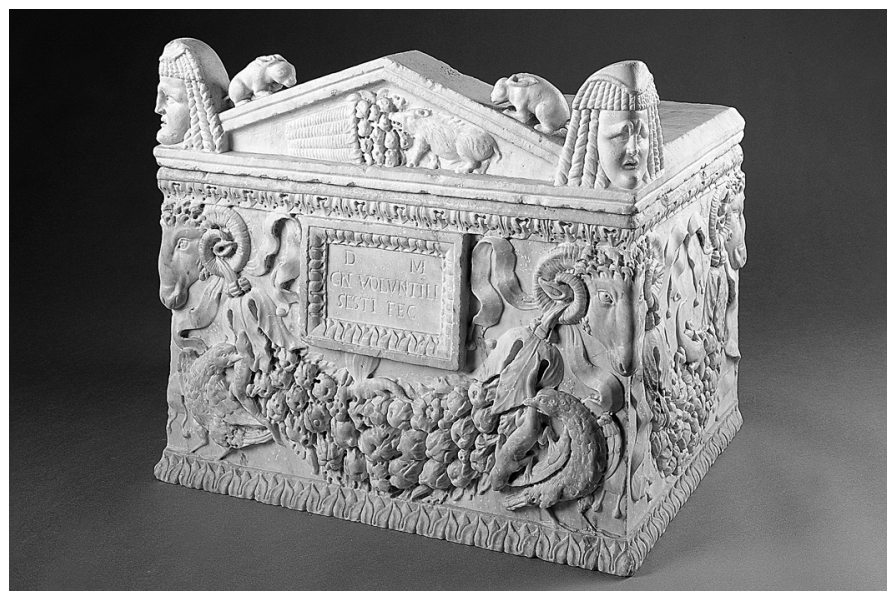

Fig. 8. Urna cineraria de Cneo Voluntilio Sesto. Mármol, 49 × 47 × $34 \mathrm{~cm}$. MAN, n..$^{\circ}$ inv. 2841.

de la cabeza y ocupan el centro de la cornamenta de la que penden las guirnaldas es un detalle que Piranesi asiduamente reproduce en los diseños de urnas. Bajo los motivos de los prótomos de carnero y, en cada uno de los lados, un ave sujeta con el pico una lagartija.

De toda la pieza, la inscripción llama especialmente la atención. Las letras aparecen de un modo tan claro y tan bien perfiladas, que ha dado lugar a pensar que fueron añadidas posteriormente al resto de la urna. No obstante, no existe ninguna señal en el recuadro donde aparece el texto inscrito que indique que haya sido borrada alguna otra inscripción anterior (Fig. 9). Además, los elementos decorativos tienen un acabado tan perfecto que no parece que existan dos momentos distintos de ejecución.

Helena Gimeno y Armin U. Stylow consideran que se trata de una urna con inscripción duplicada ${ }^{36}$, pues las tres primeras líneas del texto corresponden a una inscripción ya existente en Roma D M CN VOLVNTILI SESTI FEC/ CLAUDIA FELICITAS/ CONIVGI B $\mathrm{M}^{37}$. Este tipo de recreaciones para el mercado, copiando el texto de inscripciones antiguas, así como, inventando nuevos textos para incluirlos en piezas con el fin de venderlas como antiguas, fue una práctica muy habitual entre los falsificadores, especialmente en momentos en que la demanda de este tipo de piezas entre la clientela inglesa se incrementó y daba grandes beneficios a los talleres. Por otra parte constituye una clara evidencia de la fecha moderna en que se ha esculpido esta pieza que, junto con las demás de la serie, presentó siempre dudas a los investigadores.

${ }^{36}$ GIMENO, H. y STYLOW, A. U.: «Analecta epigraphica hispanica: manuscritos, calcos, dibujos, duplicaciones», Sylloge Epigraphica Barcinonensis III, (1999), pp. 92 y 93.

${ }_{37}$ CIL VI 29506. Emil Hübner ya lo señala al verla en la Academia de Bellas Artes. Apud Ciampinium cop. Mur. Exemplum novicium v. 1-3 in urna antiqua incisum Matriti in academia S. Fernandi vidit Huebner. RIVERO, M. del: El lapidario del Museo Arqueológico de Madrid, Valladolid, 1933, p. 93. 


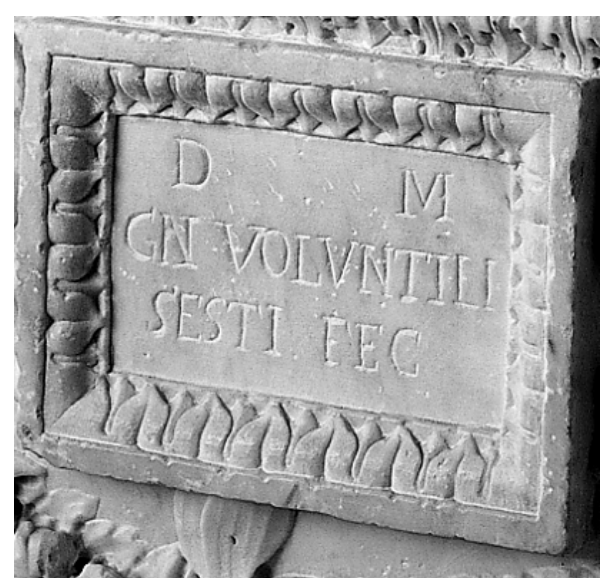

Fig. 9. Detalle del texto inscrito en la urna cineraria de Cneo Voluntilio Sesto.

El modo de ejecución de las letras difiere, como han explicado Gimeno y Stylow, con la letra antigua. Esta diferencia se nota especialmente en el ángulo medio de la $\mathrm{M}$ al no aparecer a la misma altura que las astas inicial y final, así como en la inter-punción, que en lugar de aparecer en el medio dividiendo las palabras aparece al pie del renglón. Las letras de la inscripción aparecen tan bien acabadas y claras que, han dado ocasión a suponerlas posteriores al resto de la urna; pero si se estudia bien toda ella, se puede observar cómo en el recuadro sobre el que se encuentra la inscripción no hay señal alguna de que, otra anterior haya sido borrada. Para Gimeno y Stylow, el hecho de que, por ejemplo F. Sinn ${ }^{38}$, considere esta urna de autenticidad dudosa y Schröder, a su vez, haya sugerido la posibilidad de que formase pareja junto a la urna dedicada a Antonio Maximo y Antonia Modesta, indica que no podemos afirmar con rotundidad que se traten de urnas verdaderamente antiguas ${ }^{39}$.

En cuanto al tratamiento de la decoración llama la atención la mezcla de estilos. Si bien el cimacio lésbico y las cintas que parten de los cuernos del carnero son tratadas con gran suavidad y delicadeza de líneas, dando la sensación de que el viento las está agitando, este modo de trabajar nos llevaría a pensar en una ejecución de época julio-claudia. Sin embargo, en el remate superior nos encontramos con un trépano, típico de la etapa severiana, en donde la técnica se utilizaba profusamente para conseguir efectos de claroscuro. De esta forma, nos hallamos ante una pieza en la que la cronología entre los diferentes modos de concebir los elementos decorativos variaría en torno a ciento cincuenta años. Por esta razón, hay autores que consideran esta urna de autenticidad dudosa ${ }^{40}$, mientras que otros piensan que pudiera formar pareja con otra de las urnas de este lote ${ }^{41}$.

38 SINN, F.: op. cit., 1987, p. 279

39 GIMENO, H. y STYLOW, A. U.: op. cit. p. 92.

40 SINN, F.: op. cit., 1987, p. 279.

41 MAN, Inv. 2840. 
Catalina, aunque consideraba que existían ciertas incongruencias, sin embargo, nunca pensó que pudiese tratase de una falsificación pues, según su opinión, la simbología romana aparecía interpretada con una exactitud difícil de encontrar en un falso ${ }^{42}$.

\section{URNA CINERARIA CORNELIA NYNPHA ${ }^{43}$}

Esta urna es cuadrada y presenta en su cara frontal dos trípodes rematados por máscaras teatrales. En la mitad superior, sobre un cuadro con moldura lisa aparece la inscripción en la que Cornelius Aprilis dedica el monumento funerario a Cornelio Ninfa. (Fig. 10). Posteriormente a la dedicación se añade el nombre de Albana Catela cuya relación con los anteriores no se especifica. D.M A. CoRNELIUS APRILIS CORNELIAE NYMPHE PATRONAE OTTIMAE ET ALBANE CATELE B.M.F. ${ }^{44}$. A juicio de Catalia, ET ALBANE CATELLE está escrito en fecha posterior al evidenciarse la distinta mano que el resto de la inscripción. Además, llama la atención sobre el hecho de que el ET se halla fuera de la línea de las letras, muchas de ellas además sin concluir como la de I de Aprilis ${ }^{45}$.

En la parte inferior se representa una guirnalda con ínfulas sostenida por dos amorcillos alados en cuyo interior aparece el busto de frente de una mujer joven. La tapa tiene forma de frontón pero únicamente en la parte delantera, rasgo que, como hemos visto en la urna anterior, no solía ser habitual pues lo normal es que tuviese toda ella forma de tejado a dos aguas.

La roseta en la que terminan los dos extremos de la tapa es de cinco hojas hechas con surcos y trépanos profundos que siguen un esquema muy repetido en las láminas de Piranesi ${ }^{46}$. El frontón está ocupado por una tosca cornucopia, uno de

42 CATALINA M., op. cit. p. 539.

43 MAN, n. ${ }^{\circ}$ inv. 2842. Urna cineraria. Mármol 41,25 x $37,5 \times 30 \mathrm{~cm}$.

ASF, legajo 4-87-1. En la descripción de la «Primera lista de desempaque», remitida por el marqués de la Florida y Pimentel al conde de Floridablanca el 18 de octubre de 1783 aparece descrita en el interior del caxon $\$ 3$ cuyo peso 37 y 10": Una Urna completa de mármol de un pie de alto y pie y quarto de ancho y un pie escaso de fondo con su tapa en el frente tiene al medio una inscripción de Cornelius Aprilis: Cornelia \& debajo de una guirnalda con cara en el centro dos chicos tenantes: es antigua.

${ }^{44}$ CATALINA, M.: op. cit., p. 538.

45 CIL 1863-1899, n. ${ }^{\circ}$ 16.162, vol., p. 1829 aparece recogida como Urna ex marmoro caeruleo eleganter sculpta. In hortis Mattheiorum sirm, similiter ceteri. Extat nunc Matriti apud academiam San Fernandi.

\section{D.M}

CORELIUS.APRILIS

CORELIAE NYNPHE

PATRONAE.OPTIMAE

ET.ALBANECA TILLE

B.M.F

Protome mulieris in serto quod genii alati sustinent.

Descripsit Huebner. Sirmondus Paris. 1419, 30; Gudius ms 563, 4, ed 343,4; Ptolomeus sched. 2, 42 (inde Mur. 1532, 5); Rupertus ad Reines. P. 214 (inde Renesius 18,14) descriptan a Volcammero; Seguier Paris. F 78; Mon. Matth. III p. 153 n. S, tab 73, 4 V. 5 titulo absoluto postea adiectus est.

${ }^{46}$ PIRANESI, G.B.: Vaso antico di marmo, con urna cineraria sottopostavi en Vasi, candelabri, cippi,...Roma, 1778. 

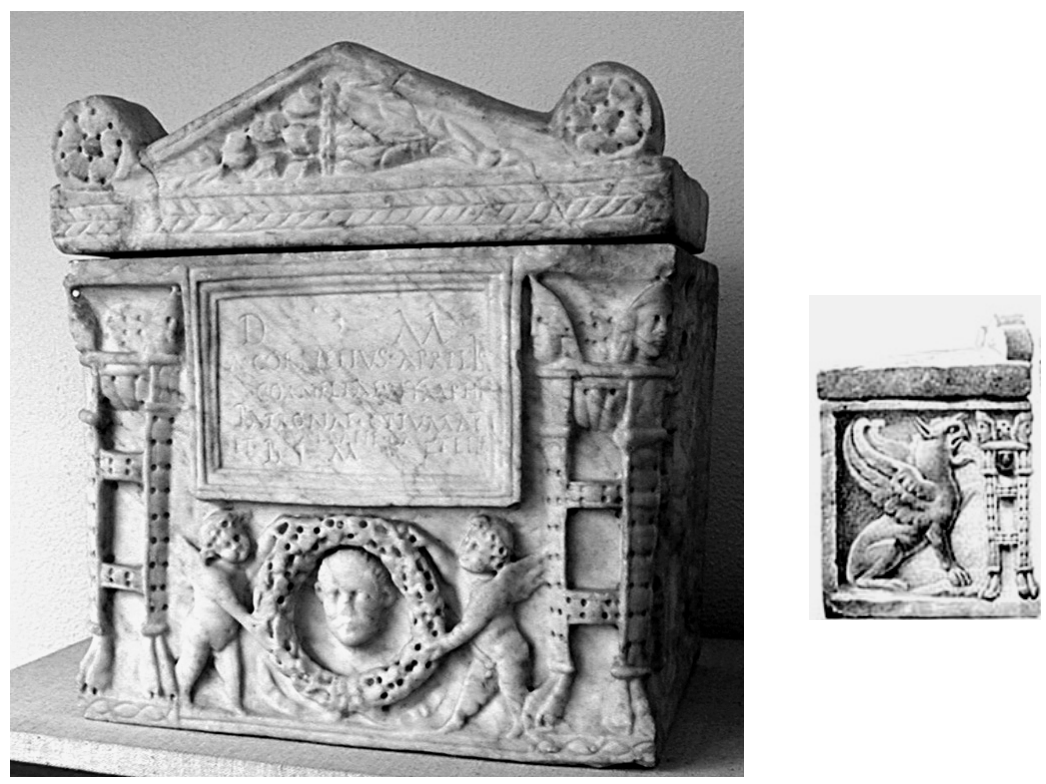

Fig. 10. Urna cineraria de Cornelia Nynpha. Mármol, 41,25 x 37,5 x $30 \mathrm{~cm}$. MAN, n. ${ }^{\circ}$ inv. inv, 2842.

los recursos decorativos que se empleaban para esta zona de la urna en las recreaciones del siglo XVIII. (Fig. 11). Mucho más tosca es la cenefa espigada de la parte inferior de la tapa que está torpemente diseñada y sigue un esquema decorativo que difícilmente podemos aceptar como antiguo. La ejecución de la decoración en relieve tiene una acusada y profunda utilización del trépano aunque utilizado con cierta torpeza, lo que ha hecho pensar que se tratase de retoques modernos. En ambos lados de la urna se reproduce un grifo. (Fig 12).

Iván Negueruela pensó que esta urna podría datarse a finales del siglo I d.C. o inicios del II, al considerar, aunque de forma dudosa, que se asemejaba a urnas procedentes de Roma u Ostia ${ }^{47}$. No obstante, desde mi punto de vista, esta hipótesis carece de fundamento pues, a pesar de que se consigue un indudable aspecto antiguo, la ejecución de los detalles, especialmente los elementos decorativos de remate, delatan rasgos propios de un taller moderno.

En esta urna hemos observado paralelismos con respecto a los diseños de Piranesi. En realidad, todas las urnas que estamos estudiando presentan motivos idénticos a los que el artista reproduce en sus estampas. Si bien, no podemos afirmar que se trata de urnas ejecutadas en el taller de Piranesi, no resulta baladí establecer este tipo de analogías pues nos ayudan a entender el tipo de negocio que existía detrás de la producción y comercialización de falsos antiguos.

47 CATAlinA, M.: op. cit., p. 539 y NEGUERUELA, I.: op. cit., p. 269. 


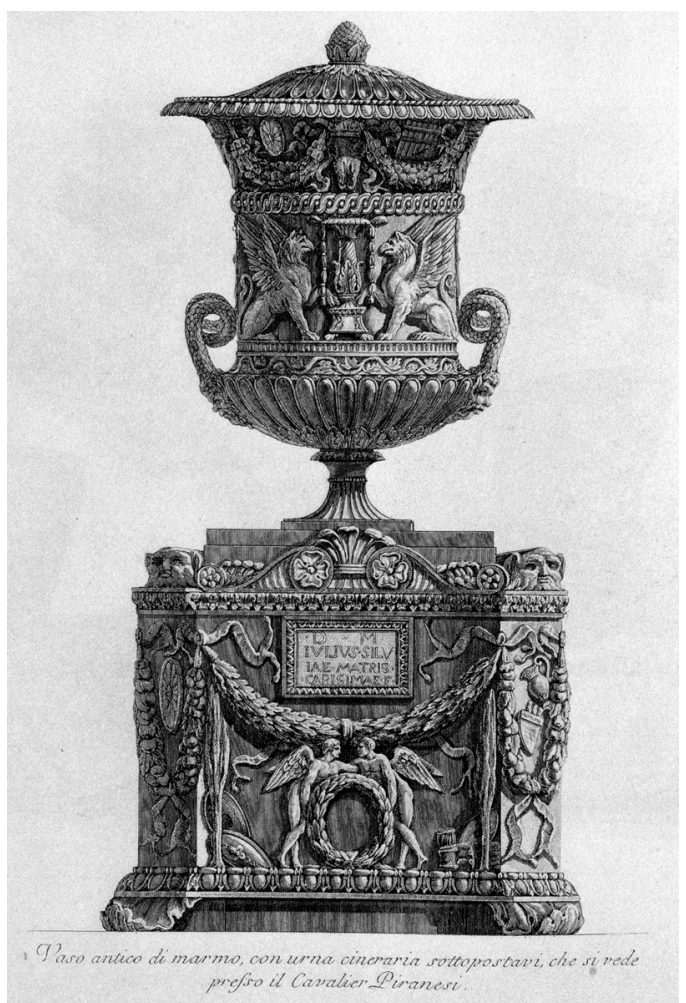

Fig. 11. Giovanni Battista Piranesi, Vaso antico di marmo, con urna cineraria sottopostavi che si vede presso il Cavalier Piranesi, en Vasi, candelabri, cippi, sarcofagi, tripodi, lucerne, ed ornamenti antichi disegnati ed incisi dal Cav. Gio. Batt. Piranesi, Roma, 1778.

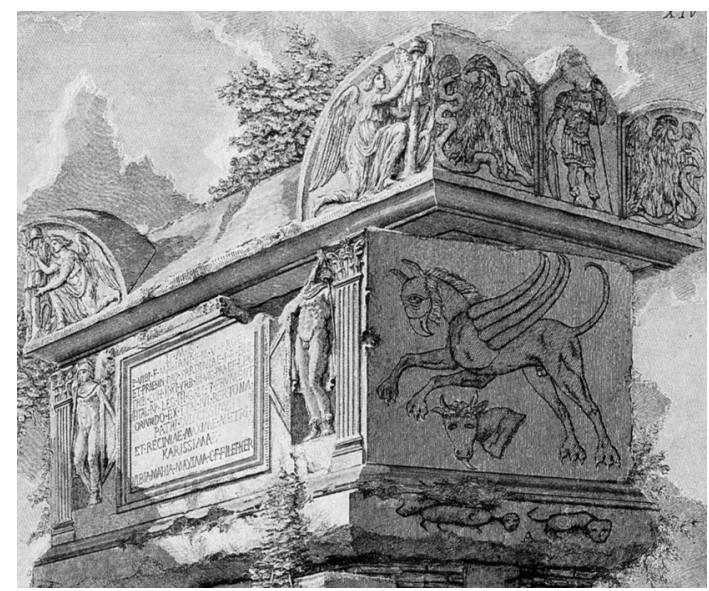

Fig. 12. Giovanni Battista Piranesi. Detalle de un grifo que aparece en el lateral de un sepulcro representado en la estampa "Veduta di un Sepolcro fuori di Porta del Popolo sull'antica Via Cassia», en Le Antichità Romane III, Roma, 1756. 


\section{URNA CINERARIA DE ANTONIA MAXUMA ${ }^{48}$}

En la relación de objetos procedentes de Málaga que se realizó en la Academia de San Fernando figura la siguiente descripción de esta urna: Otra entera, también de mármol, con su tapa, de pie y tres cuartas de largo, pie y cuarto de ancho y media vara de alto: en el frente un festón de avecitas sobre él, y encima la inscripción Antoniae Maxumae Antonia Moedestae Laurentius Gener maritus ex testamento. (Fig. 13).

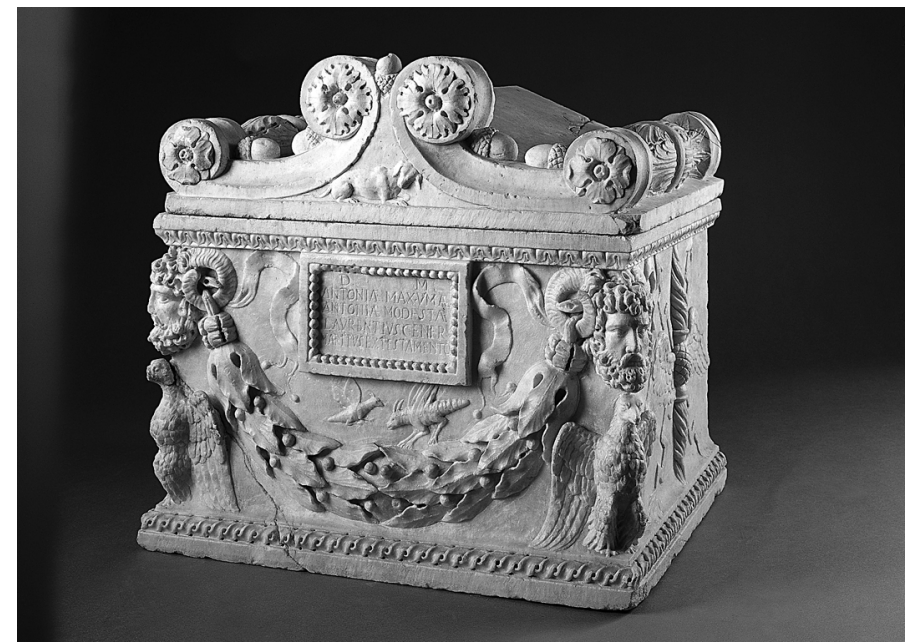

Fig. 13. Urna cineraria de Antonia Maxuma, mármol, 49 × 49 × $37 \mathrm{~cm}$. MAN, n.o inv. 2840.

Esta urna se caracteriza por la presencia en cada uno de los ángulos de cabezas de Júpiter-Ammón. La forma en la que la oreja se coloca en el centro de la espiral de los cuernos y toda la distribución de los elementos decorativos en la urna son muy habituales en los grabados de Piranesi. (Fig. 14). Algunos elementos decorativos de carácter menor como los animalillos, que suele colocar encima de las guirnaldas o en el frontón de la tapa, nos indican que estamos ante una obra del círculo de este artista. El perro echado lo encontramos repetido en numerosos ejemplos de los grabados piranesianos pretendiendo dar un significado al conjunto de la decoración, ya que el perro era un animal dedicado a Esculapio en el mundo romano pero en las tumbas rara vez figura con este significado pues, lo más común, era ponerle como símbolo de la fidelidad o como ser muy querido por el difunto. (Fig 15). Según Catalina, en esta ocasión pudiera tratarse de una representación de la muerte al aparecer dormido. El águila en los sepulcros simboliza, o bien que el difunto se había distinguido en el ejército por las armas o la inmortalidad del alma, o

48 MAN n. ${ }^{\circ}$ inventario 2840. Urna cineraria $49 \times 36 \times 48 \mathrm{~cm}$.

ASF, legajo 4-87-1. En la relación de objetos procedentes de Málaga que se realizó en la Academia de San Fernando figura la siguiente descripción de esta urna. 

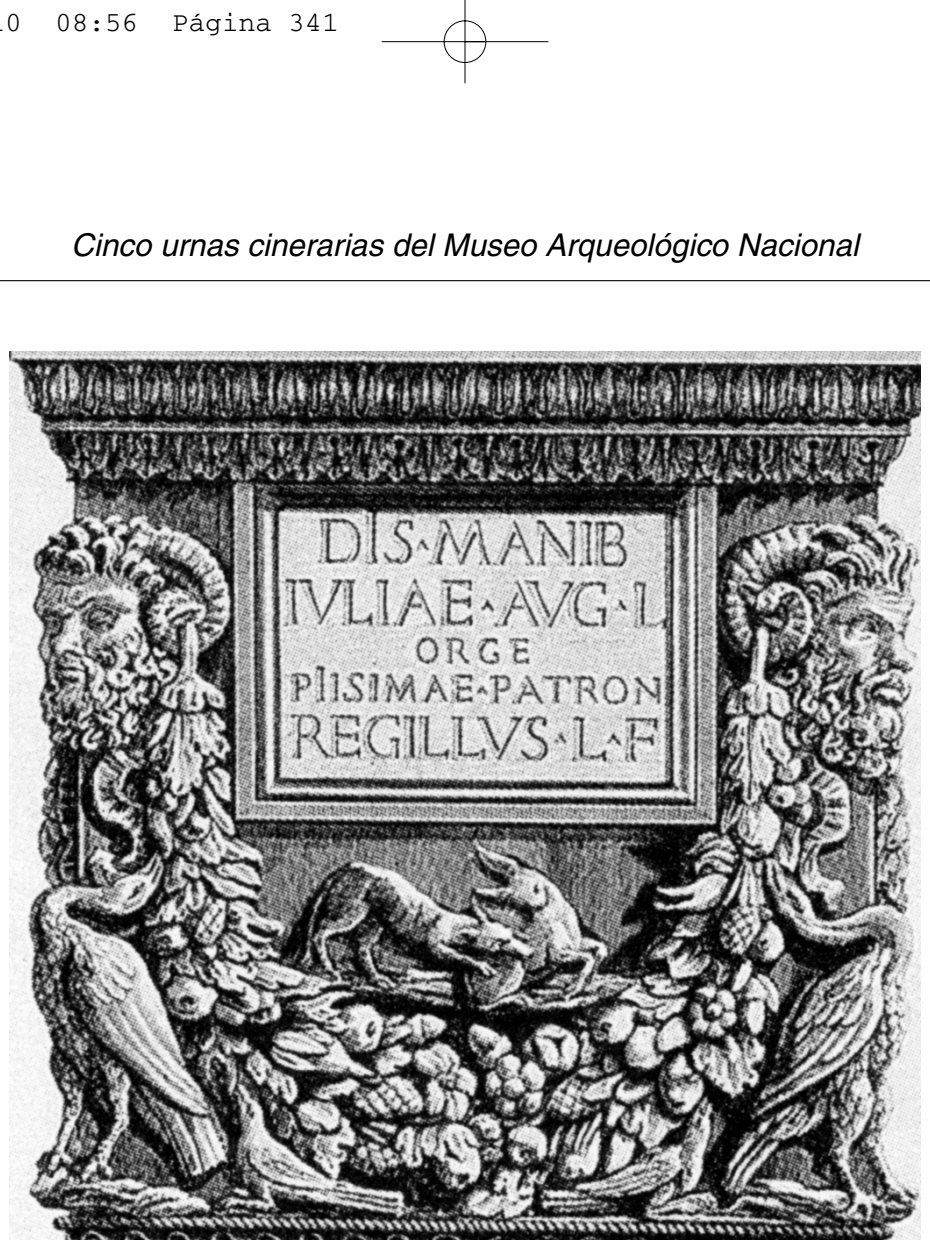

Fig.14. Giovanni Battista Piranesi, Detalle de la estampa «Vaso Antico di Marmo adornato di eccelenti Sculture...” dedicado al Signor Thomasso Moore Slade Cavaliere Inglese» en Vasi, candelabri, cippi, sarcofagi, tripodi, lucerne, ed ornamenti antichi disegnati ed incisi dal Cav. Gio. Batt. Piranesi, Roma, 1778.

el triunfo sobre la muerte, aunque en este caso en concreto se considera que el águila indica la devoción especial que el difunto tenía a Júpiter-Ammon.

Helena Gimeno y Armin U. Stylow ${ }^{49}$ observaron que en esta inscripción era una copia de otra que había aparecido algunos años antes en Portugal, en Ferreira do Zézere (Santarem), y que, a su vez, había sido reutilizada en una ermita de San Pedro de Castro ${ }^{50}$. El hecho de que fuese publicada el 18 de junio de 1773 en el periódico La Gaceta de Portuga $/{ }^{51}$, es decir, con anterioridad la presa del Westmorland, conduce a pensar que pudiese haber sido esculpida a su llegada a España.

49 GIMENO, H. y STYLOW, A. U.: op. cit, p. 92.

50 Sobre el hallazgo véanse DE AZEVEDO P.A.: «Noticias archeologicas do seculo XVIII», AP 5 (1910), p. 86 de donde lo recoge EE IX 335 y PEREIRA, E. A.: «Noticias Arqueológicas na Gazeta de Lisboa», Conimbriga 2-3 (1960-61), pp. 328-329, n. ${ }^{\circ}$.

51 (is) M(anibus)

Anton(a)e Maxum(a)e

Antoni(a) Modesta mat-

er et L(ucius) Avillius Celer

maritus ex testamen-

to $f($ aciendum) $c$ (uravit) 


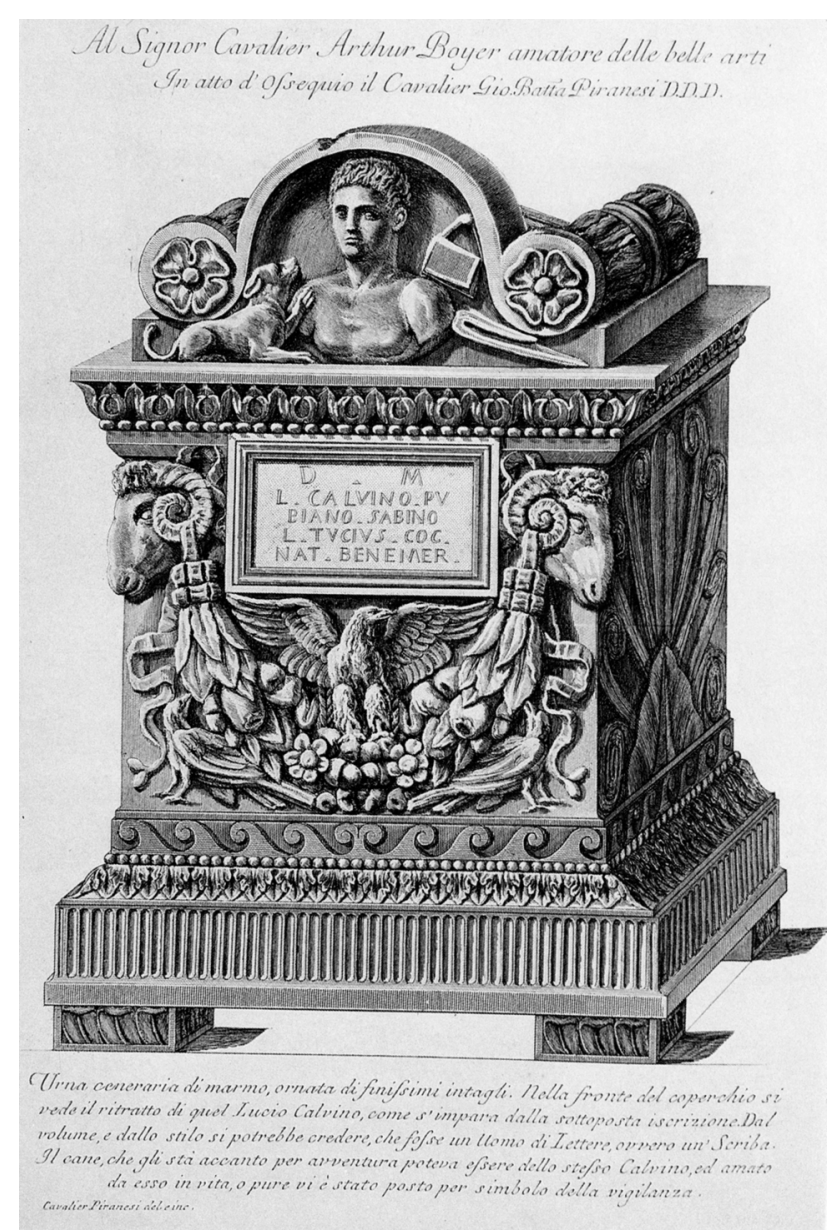

Fig. 15. Giovanni Battista Piranesi, Urna ceneraria di marmo, ornata di finissimi intagli... dedicada al «Signor Cavalier Arthur Boyer amatore delle belle arti» en Vasi, candelabri, cippi, sarcofagi, tripodi, lucerne, ed ornamenti antichi disegnati ed incisi dal Cav. Gio. Batt. Piranesi, Roma, 1778.

Amin U. Stylow cree que puede tratarse de una urna traída de Italia, como así se ha documentado en la propia Academia, pero a la cual se añade la inscripción suponiendo que se trate de una pieza antigua. Propone que el texto debió de ser esculpido entre 1773 fecha en que salió publicada en la Gaceta de Portugal y 1783, año en que fue trasladada a la Academia de Bellas Artes. Esta última fecha podría adelantarse algo más porque la captura del Westmorland tuvo lugar durante los últimos días del mes de diciembre de 1778 y los primeros días de enero de $1779^{52}$. No obstante, tal y como atestiguan los documentos la urna venía ya con la inscripción desde Italia.

52 SUÁREZ HUERTA, op. cit., 2002, pp. 49-68. 
Las consideraciones que han hecho algunos autores sobre la posibilidad de que se trate de urnas falsas, retocadas o manufacturas renacentistas, no son sino el resultado del desconcierto que producen cuando se las pretende analizar como obras antiguas y se ven en ellas ciertos elementos que no encajan con el acabado, forma de tallar e incluso interpretación de los motivos decorativos. Los talleres romanos del siglo XVIII elaboraban los motivos antiguos con manufactura y acabados diversos. Interesaba reproducir la pieza con la mayor fidelidad posible y, para ello, se requería una buena técnica escultórica y una gran pericia de ejecución. No obstante, los escultores no eran arqueólogos, y el estudio de la Antigüedad estaba aún lejos de convertirse en una disciplina científica, de manera que los artistas no sentían ningún pudor a la hora de mezclar todos aquellos elementos que conocían precisamente por su contacto directo con las obras antiguas. A pesar de su escasa fidelidad histórica, no debemos olvidar que muchas de estas obras han logrado engañar durante siglos al ojo del entendido. (Fig. 16).

El caso del cargamento de antigüedades que viajaban en el Westmorland constituye un punto de inflexión puesto que habría de interrogarse acerca de hasta que punto los artistas contemporáneos empezaron a ponerse de moda y los coleccionistas de la época empezaron a adquirir obras realizadas en aquellos momentos. Como hemos advertido Bartolomeo Cavaceppi vivió del negocio de las antigüedades aunque sus ideas estéticas comenzaban a encaminarse hacia otros derroteros y Giovanni Battista Piranesi logró , gracias a este gran negocio de incipientes «souvenir turísticos", plasmar lo que había siempre manifestado en su obra teórica Parere su l'architettura (1765), cuya principal máxima no era otra que "Quella pazza libertà di lavorare a capriccio». Las urnas cinerarias que hemos analizado en este artículo no son otra cosa que estos caprichos imaginados por la mente de este artista, aunque no podemos demostrar documentalmente que, estas obras en concreto, saliesen de alguno de los talleres romanos destinados a la demanda de souvenirs all'antica del Grand Tour.

Es destacable el contraste existente entre el profundo interés por las antigüedades que se advertía entre los viajeros a su llegada a Italia y la escasa curiosidad por la misma en otros países que, como Francia e Inglaterra, también cuentan con vestigios de este pasado de esplendor. Las urnas cinerarias junto al resto de las piezas como candelabros, chimeneas ${ }^{53}$ y guaches de monumentos antiguos de Roma ${ }^{54}$ constituyen un guiño creativo al universo creativo y homenaje a uno de los más grandes defensores de la Antigüedad romana de Piranesi que ya en aquella época formaba parte del imaginario colectivo de los viajeros.

De la misma forma que los arquitectos especializados en la creación de decorados para los rodajes de largometrajes históricos durante la época dorada de Hollywood han contribuido a crear una falsa memoria colectiva acerca de cómo debían ser, visualmente hablando, cada uno de los períodos históricos que retrata la cinematografía ${ }^{55}$, este tipo de piezas, características de la época de esplendor del

53 WILTON-ELY, J.: Piranesi as Arquitect and Designer, New Haven y Londres, 1993.

54 SUÁREZ HUERTA, A.M.: Arte y Artistas del Westmorland. Un caso singular del Grand Tour (Tesis doctoral, s.p.), Universidad Complutense, Madrid, 2004, pp.198-244.

55 RAMíREZ, J. A.: La arquitectura en el cine. Hollywood, la Edad de Oro, Madrid, Alianza, 1993. 




Fig. 16. Bartolomeo Cavaceppi, Urnas destinadas al mercado inglés. El esquema compositivo es similar al de la urna dedicada a Cneo Voluntilio Sesto y Antonia Maxuma en Raccolta d'antiche statue busti teste cognite ed altre sculture antiche suelte ristaurate da Bartolomeo Cavaceppi scultore romano, vol. III, Roma, 1772.

Grand Tour, explican cómo la obra gráfica de Piranesi llegó a convertirse en el punto de referencia fundamental de la imagen que se tenía acerca de lo que debió de ser la Roma Imperial. A pesar de que, en ocasiones, el contacto directo quizá desilusionaba las expectativas de todos aquellos que pretendían encontrarse con una Roma configurada tal y como la imaginaba el artista veneciano, lo cierto es que lo que primaba eran aquellos objetos que imaginó susceptibles de ser admirados y adquiridos por todos aquellos que se acercaban y quería llevarse un pedacito del Alma Cittá. Ante esto tanto Bartolomeo Cavaceppi como Giovanni BattistaPiranesi supieron sacar partido de las circunstancia creando casi, podríamos decirlo así, la primera industria del souvenir. 